\title{
Effects of Some Selected Solvent Extracts of Avocado Pear (Persea americana) on Cholesterol/HDL Ratio in Albino Rats
}

\section{Olagunju $\mathrm{HT}^{1 *}$, Oruambo $\mathrm{IF}^{2}$, Oyelowo $\mathrm{HO}^{3}$ and Obediah $\mathrm{GA}^{3}$}

${ }^{1}$ Department of Chemistry, Rivers State University, Nkpolu-Oroworukwo, Port Harcourt, Rivers State, Nigeria

${ }^{2}$ Department of Biochemistry, Rivers State University, Nkpolu-Oroworukwo, Port Harcourt, Rivers State, Nigeria

${ }^{3}$ Department of Biochemistry, Usmanu Danfodiyo University, Sokoto State, Nigeria

\begin{abstract}
The effects of some selected solvents extracts of Avocado Pear (Persea americana) on Cholesterol/HDL ratio of albino rats was investigated. The avocado fruit was dried at room temperature and was extracted with ethanol and $\mathrm{N}$-hexane using soxhlet extractor. The phytochemical screening of ethanol, aqueous and $\mathrm{N}$-hexane extracts reveals the presence of Alkaloid, Tannin, Phytate, Phenol, Oxalate, Steroid, Saponin and Glycoside. The quantitative analysis shows that Alkaloid; Aqueous Extract $0.96 \%$, Ethanol 1.37\%, N-hexane 1.81\%, Phytate; Aqueous Extract $0.68 \%$, Ethanol 1.47\%, N-hexane 0.88\%, Saponin; Aqueous Extract 1.28\%, Ethanol 0.76\%, N-hexane 1.06\%, Phenol; Aqueous Extract 2.75\%, Ethanol 2.43\%, N-hexane 1.14\%, Oxalate; Aqueous Extract 3.36\%, Ethanol $2.81 \%$, N-hexane 2.53\%, Tannin; Aqueous Extract $0.69 \%$, Ethanol $1.36 \%$, N-hexane $0.72 \%$, Steroid; Aqueous Extract $1.66 \%$, Ethanol $2.04 \%$, $\mathrm{N}$-hexane $2.58 \%$, Glycoside; Aqueous Extract $0.14 \%$, Ethanol $0.52 \%$, N-hexane $0.39 \%$. Eighteen male albino rats were divided into three groups of which six rats per group; the first group were given ethanol extracts while the control receive ethanol, the second group were given $\mathrm{N}$-hexane extracts while the control receive $\mathrm{N}$-hexane and the third group were given aqueous extract while the untreated were feed ad libitum which serve as the control. A lipid profile test was carried out in the serum of albino rats in which the values of HDL, TRIG, LDL, CHOL and VLDL was recorded. The TC/HDL ratio was calculated by dividing Cholesterol with $\mathrm{HDL}$ and was plotted on a bar chart. Aqueous extract of avocado has the highest concentration in oxalate and phenol compared to ethanol and $\mathrm{N}$-hexane extracts. The Total Cholesterol/HDL Ratio of untreated albino rats feed ad libitum has a ratio of 5.468 which is a high risk heart disease. Albino rats fed with aqueous extract has a ratio of 4.615 while ethanol extracts has a ratio of 4.623 , they both fell in a low risk heart disease. $\mathrm{N}$-hexane extract has a ratio of 3.553 which falls below average for heart disease. In conclusion, the result obtained from phytochemical concentration shows that oxalate and phenol has the highest percentage in all the solvent extracts of avocado. The cardiovascular disease marker on TC/HDL Ratio of male albino rats fed with aqueous and ethanol extracts fell within the low risk acceptable range while $\mathrm{N}$-hexane extracts fell in very low average risk for CVD. The result shows that Avocado (Persea americana) reduces TC/HDL Ratio as well as boosting the "good cholesterol" (HDL) which is good for cardiovascular health.
\end{abstract}

Keywords: Persea americana; TC/HDL ratio; Cardiovascular disease

\section{Introduction}

Diet low in cholesterol is one of the essential ways to improve the cardiovascular status. Health issues have been raised because of the strong correlation between high levels of cholesterol in the body and cardiovascular disease. Cholesterol is a soft waxy substance found in every living cell of the body and also one of the building blocks of the cell membrane. It helps to digest fat, strengthen cell membranes and make hormones [1]. Cholesterol are carried around the body by protein when combined they are called lipoproteins. Lipoproteins help to transport fat and show varying patterns that correlate with the risk of having fatal cardiovascular disease. There are two major broad classes of lipoproteins which are High Density Lipoprotein (HDL) and Low Density Lipoprotein (LDL). LDL is considered the "bad" while HDL is considered the "good" cholesterol [2].

Cardiovascular markers also known as cardiac markers are biomarkers measured to evaluate heart function or heart disease. Heart disease or cardiovascular disease (CVD) is one of the leading cause of morbidity and motility from infancy to old age. Early detection and treatment of risk factors helps to prevent the spread of disease as well as morbidity improvement [3]. The Total Cholesterol/HDL Ratio is more indicative of cardiovascular disease than TC (total cholesterol). The amount of HDL and LDL in the blood are added together which indicates the total amount of cholesterol (TC). Cholesterol level can be reduced by eating vegetables and fruits like avocados, walnut, coconut etc. Research has shown that eating fruit like avocado can lower the amount of fat in the blood, thereby reducing the dangerous LDL cholesterol in the blood at the same time increasing the more beneficial HDL cholesterol. The incidence of cardiovascular disease (CVD) is on the increase in Nigeria population due to high cholesterol. The consumption of avocado has been related to benefits some cardiovascular risk factors as well as to the improvement of the dietary quality and nutrient intake of individuals by increasing the consumption of monounsaturated fatty acid (MUFA), dietary fiber etc.

The fruit of Persea americana which is commonly known as Avocado is a native tree of South Central Mexico which is classified as a flowering plant Lauraceae family [4]. Avocado is the fattiest plant food in existence and contains monounsaturated fatty acid as well as lipids such as phytosterols, $ß$-sitosterol, campesterol, and stigmasterol. The $ß$-sitosterol helps to lower LDL level and raises HDL level. Avocados

*Corresponding author: Olagunju HT, Department of Chemistry, Rivers State University, Nkpolu-Oroworukwo, Port Harcourt, Rivers State, Nigeria, Tel: +2348131527684; E-mail: helentomilola@yahoo.co.uk

Received: October 17, 2017; Accepted: October 28, 2017; Published October 06, 2017

Citation: Olagunju HT, Oruambo IF, Oyelowo HO, Obediah GA (2017) Effects of Some Selected Solvent Extracts of Avocado Pear (Persea americana) on Cholesterol/HDL Ratio in Albino Rats. Biochem Anal Biochem 6: 342. doi: 10.4172/2161-1009.1000342

Copyright: (c) 2017 Olagunju HT, et al. This is an open-access article distributed under the terms of the Creative Commons Attribution License, which permits unrestricted use, distribution, and reproduction in any medium, provided the original author and source are credited. 
is one of the few fruits that give "good" fats because it contains monounsaturated fatty acid which is mainly oleic acid and it also reduces the risk of cardiovascular disease (CVD). Oleic acid is one of the most abundant fatty acid which is known to be effective in lowering serum cholesterol levels and low density lipoprotein [5].

\section{Materials and Method}

\section{Collection of fruit}

The fruit of Persea americana (Avocado Pear) was obtained from rumuokoro market Port Harcourt, Rivers State, Nigeria and brought to the laboratory.

\section{Experimental animals}

Eighteen male albino rats weighting between 150-200 g were obtained from the animal farm in University of Port Harcourt (UNIPORT), Nigeria. They were housed in standard rat cages in the department. They were given water and feed ad libitum and kept under laboratory conditions for an acclimatization period of seven days before the research commenced.

\section{Preparation of sample}

The fruits were thoroughly washed and the pericarp (peel) was removed from the mesocarp (flesh) leaving the mesocarp and the endocarp (seed). The mesocarp (flesh) were cut into smaller pieces and air dried for 5 days at ambient temperature. The dried monocarp was ground into powdered form using porcelain mortar and pestle.

\section{Extraction}

The powdered sample was extracted exhaustively with n-hexane and ethanol using soxhlet apparatus. The extracts were concentrated using rotary evaporator and stored in a clean sterile vials until required.

\section{Phytochemical analysis}

Phytochemical screening was carried out on the extracts using standard procedures of Harborne [6] and Trease, et al. [7]. Quantitative analysis was carried out using standard methods. Alkaloids were determined by the method of Harbone [6]. Phytate was determined by the method of Harbone [6]. Saponin was determined by the method of Obadoni and Ochuko [8]. Phenol was determined by the method of Edeoga et al. [9]. Oxalate was determined by the method of Chinma and Igyor [10]; Ihekoronye and Ngoddy [11]. Tannins were determined by the method of Edeoga, et al. [9]. Steroid was determined by the method of Nwosu [12]. Glycoside was determined by the method of Inuwa et al. [13].

\section{Treatment of animals}

Eighteen male albino rats were divided into three feeding groups (I-III) of 6 rats per group. Group I were fed aqueous extract of avocado pear while the untreated serve as control. Group II were fed ethanol extract of avocado pear while the control were given ethanol. Group III were fed $\mathrm{N}$-hexane extract of avocado pear while the control were given $\mathrm{N}$-hexane. At the end of the two weeks and after an overnight fast, blood was withdrawn via cardiac puncture when animals were rendered unconscious under pentobarbital anesthesia. The blood was collected in lithium heparin bottles and lipid profile test were carried out.

\section{Lipid profile test}

Serum cholesterol, high density lipoprotein (HDL) and triglyceride were determined using Randox kits produced by Human DiagnosticGermany [14-16]. The serum very low density lipoprotein (VLDL) and low density lipoprotein (LDL) were calculated using Friedewald formula [17].

\section{Statistical analysis}

The mean values of High density lipoprotein (HDL), Low density lipoprotein (LDL), Cholesterol, Very low density lipoprotein (VLDL) and Triglyceride in the three groups were calculated. Values are expressed as Mean $\pm \mathrm{SD}$.

\section{Result and Discussion}

The result obtained from qualitative phytochemical constituents of avocado (Persea americana) extracts in Table 1 show that it contains Alkaloid, Phytate, Saponin, Phenol, Oxalate, Tannins, Steroid and Glycoside.

The quantification of phytochemical in Table 2 shows that aqueous extract of avocado (Persea americana) has the highest concentration in oxalate compared to ethanol and n-hexane extracts. Phenol has the highest percentage in aqueous extracts compared to ethanol and $\mathrm{n}$-hexane extracts. High percentage of phenol is in agreement with the findings of Dabas et al. [18] who reported that avocado are rich in phenol which plays a major role in body system of an individual The presence of phenol in avocado fruit helps to reduce cardiovascular disease (CVD) risk by reducing oxidative and inflammatory stress [19].

\begin{tabular}{|c|c|c|c|c|}
\hline S/No. & Test & Aqueous Extract & Ethanol Extract & N-hexane Extract \\
\hline 1 & Alkaloid & + & ++ & ++ \\
\hline 2 & Phytate & + & ++ & + \\
\hline 3 & Saponin & ++ & + & ++ \\
\hline 4 & Phenol & +++ & +++ & ++ \\
\hline 5 & Oxalate & ++++ & +++ & +++ \\
\hline 6 & Tannin & + & ++ & + \\
\hline 7 & Steroid & ++ & +++ & +++ \\
\hline 8 & Glycoside & + & + & + \\
\hline
\end{tabular}

Table 1: Qualitative screening of avocado (Persea americana) extracts.

\begin{tabular}{|c|c|c|c|c|}
\hline S/No. & Test & Aqueous Extract & Ethanol Extract & N-hexane Extract \\
\hline 1 & Alkaloid (\%) & 0.96 & 1.37 & 1.81 \\
\hline 2 & Phytate (\%) & 0.68 & 1.47 & 0.88 \\
\hline 3 & Saponin (\%) & 1.28 & 0.76 & 1.06 \\
\hline 4 & Phenol (\%) & 2.75 & 2.43 & 1.14 \\
\hline 5 & Oxalate (\%) & 3.36 & 2.81 & 2.53 \\
\hline 6 & Tannin (\%) & 0.69 & 1.36 & 0.72 \\
\hline 7 & Steroid (\%) & 1.66 & 2.04 & 2.58 \\
\hline 8 & Glycoside (\%) & 0.14 & 0.52 & 0.39 \\
\hline
\end{tabular}

Table 2: Quantitative contents (\%) of avocado (Persea americana) extracts.

\begin{tabular}{|c|c|c|c|c|}
\hline Sample & HDL & TRIG & LDL & CHOL \\
\hline Control & $0.775 \pm 0.156$ & $1.411 \pm 0.163$ & $6.879 \pm 0.011$ & $4.238 \pm 0.067$ \\
\hline Aqueous Extract & $1.228 \pm 0.221$ & $1.912 \pm 0.779$ & $7.764 \pm 0.640$ & $5.667 \pm 0.067$ \\
\hline Ethanol Control & $1.245 \pm 0.706$ & $1.982 \pm 0.329$ & $7.275 \pm 0.957$ & $5.130 \pm 0.101$ \\
\hline Ethanol Extract & $1.232 \pm 0.575$ & $1.562 \pm 0.472$ & $7.637 \pm 0.033$ & $5.696 \pm 0.756$ \\
\hline N-hexane Control & $1.123 \pm 0.604$ & $2.061 \pm 0.757$ & $8.247 \pm 1.465$ & $6.188 \pm 0.517$ \\
\hline N-hexane Extract & $1.258 \pm 0.438$ & $2.137 \pm 1.027$ & $6.698 \pm 0.981$ & $4.470 \pm 0.076$ \\
\hline Values are expressed as Mean \pm SD & & \\
\hline
\end{tabular}

Table 3: Lipid profile of albino rats fed with various extracts of avocado (Persea americana). 


\begin{tabular}{|c|c|c|c|}
\hline Sample & CHOL & HDL & CHOL/HDL Ratio \\
\hline Control & 4.238 & 0.775 & 5.468 \\
\hline Aqueous Extract & 5.667 & 1.228 & 4.615 \\
\hline Ethanol Extract & 5.696 & 1.232 & 4.623 \\
\hline N-hexane Extract & 4.47 & 1.258 & 3.553 \\
\hline
\end{tabular}

Table 4: Total Cholesterol/HDL Ratio of albino rats.

\section{TC/HDL RATIO}

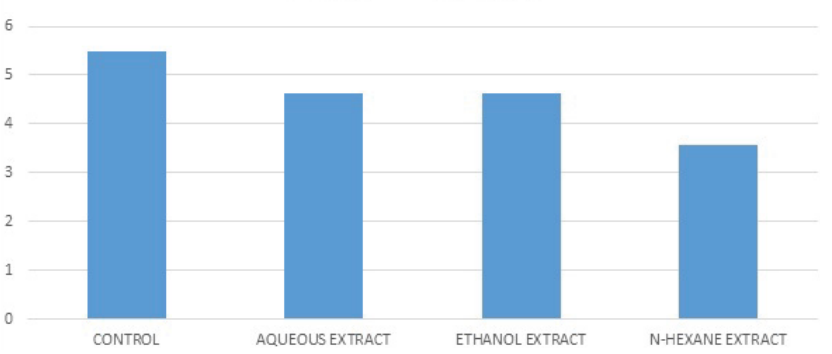

Figure 1: A bar chart showing total cholesterol/HDL ratio of albino rats.

The result obtained from lipid profile test of albino rats is shown in Table 3.

The Total Cholesterol/HDL Ratio of albino rats is shown in Table 4. The result shows that the untreated rats fed ad libitum has a cholesterol ratio of 5.468 which is a high risk heart disease. Albino rats fed with aqueous extract of avocado (Persea americana) has a cholesterol ratio of 4.615 and ethanol extract has 4.623 both fell in a low risk heart disease. The n-hexane extract has a cholesterol ratio of 3.553 which falls below average for heart disease.

The result obtained from plotting a bar chart of lipid profile test in Total Cholesterol/HDL Ratio is shown in Figure 1. The bar chart of Total Cholesterol/HDL Ratio shows that control has an elevated level compared to aqueous extract, ethanol extract and $\mathrm{N}$-hexane extract.

\section{Conclusion}

From the results obtained oxalate and phenol has the highest concentration of phytochemicals in all the solvent extracts of avocado. The cardiovascular disease marker on TC/HDL Ratio of male albino rats fed with aqueous and ethanol extracts fell within the low risk acceptable range while $\mathrm{N}$-hexane extracts fell in very low average risk for cardiovascular heart disease. The result shows that $\mathrm{N}$-hexane extract has the highest HDL level when compared to control, ethanol extract and aqueous extract. Research has shown that HDL has the ability to promote efflux of cholesterol from cells which may minimize the accumulation of foam cells in the artery wall thereby preventing the development of atherosclerosis (CVD). It is now established that diet high in cholesterol and LDL (bad cholesterol) causes an increase in Total Cholesterol/HDL ratio which enhance the risk of cardiovascular disease $[20,21]$. Therefore avocado pear (Persea americana) reduces TC/HDL Ratio thereby boosting the "good cholesterol" (HDL) which is good for cardiovascular health.

\section{References}

1. Schober SE, Carroll MD, Lacher DA, Hirsch R (2006) High serum cholesterolan indicator for monitoring cholesterol lowering efforts. NCHS Data Brief 2: 1-8.

2. American Heart Association (2013) What your cholesterol levels mean.

3. Bamba V (2014) Update on screening, etiology, and treatment of dyslipidemia in children. The Journal of Clinical Endocrinology \& Metabolism 99: 3093-3102.

4. Morton JF (1987) Avocado; In: Fruits of Warm Climates. Creative Resource Systems, Inc., Winterville, NC and Centre for New Crops \& Plant Products Department of Horticulture and Landscape Architecture, Purdue University West Lafayette, IN, pp: 91-102.

5. Alvarado (2003) Oleic Acid. Molecular Expressions: Science, Optics and You.

6. Harbone JB (1973) phytochemical methods. A guide to modern techniques of plant analysis, Springer Science \& Business Media, pp: 1-13.

7. Trease GE, Evans WC (1989) Pharmacognosy. Brailliar Tindal Macmillan Publisher, p: 530.

8. Obdoni BO, Ochuko PO (2001) Phytochemical Studies and Comparative Efficacy of the Crude Extract of some Homeostatic Plants in Edo and Delta States of Nigeria. Glob J Pure Appl Sci 8: 203-208.

9. Edeoga HO, Okwu DE, Mbaebie BO (2005) Phytochemical constituent of some Nigeria medical plants. Africa Journal Biotechnology 4: 685-688.

10. Chinma CE, Igyor MA (2007) Micronutrients and anti-nutritional contents of selected tropical vegetables grown in Southeast, Nigeria. Niger Food J 25: 111116

11. Ihekoronye AL, Ngoddy PO (1985) Tropical fruits and Vegetablesll in Integrated Food Science and Technology for the Tropics. Macmillian Publishers. London, pp: 293-304.

12. Nwosu JN (2011) The effects of processing on the anti-nutritional properties of Oze Bosqueia angolensis seed. Journal of American Science 71: 16.

13. Inuwa HM, Aina VO, Gabi B, Aimola I, Toyin A (2011) Comparative determination of anti-nutritional factors in Groundnut oil and Palm oil. Advance Journal of Food Science and Technology 34: 275-279.

14. Schettler G, Nussel E (1975) Massnahmen Zur Prevention der Artherosklerose. Arb Med Soz Med Prav Med 10: 25.

15. Trinder $P$ (1981) Oxidase determination of plasma cholesterol as cholest-4-en3-one using isooctane extraction. Ann Clin Bioche 18: 64-70.

16. Trinder P, Webster D (1984) Determination of HDL-cholesterol using 2,4,6-tribromo-3hydrobenzoic acid with a commercial CHOD-PAP reagent. Ann Clin Biochem 21: 430-433.

17. Friedwald WT (1972) Methods for the determination of LDL Cholesterol. Clin Chem 18: 499-502.

18. Dabas D, Shegog RM, Ziegler GR, Lambert JD (2013) Current Pharmaceutical Design 19: 6133-6140.

19. Chong MF, Macdonald R, Lovegrove JA (2010) Fruit polyphenols and CVD risk: A review of human intervention studies. British Journal of Nutrition 104 S28-S39.

20. Genest JJ, Martin-Munley SS, Mc-Namara JR, Ordovas JM, Jenner J, et al. (1992) Familial lipoprotein disorders in patients with premature coronary artery disease. Circulation 85: 2025-2033.

21. Kamal H (1975) Encyclopedia of Islamic medicine. Cairo: General Egyptian Book Organization. 